\title{
Corporate Internal Management Information System
}

\author{
Shuli Huang \\ College of Information Engineering, Jiangxi University of Technology, Jiangxi Nanchang
}

Keywords: Internal management ; Computer technology; Construct system; JavaBean technology

\begin{abstract}
The system is researched and developed in combination with the current development of computer technology, to meet the demands of the medium and small-sized enterprises for informatization of internal management. The system is constructed by use of JavaBean technology for JSP dynamic webpage making. It is designed in B/S development model, and adopts Tomcat as JSP server, and MyEclipse as the development environment, while DB 8.2 is used for the backend database. The major part of the system is constructed in the structure of customer end-middle layer (module layer) ---data base. The system administrator can increase, delete, revise and query the information, while the common users cannot take information retrieval. It has been proved by practice that the system developed corresponds to the demands of the enterprises for internal management and has a great application prospect.
\end{abstract}

\section{Overview}

With the rapid development of China's economy, the competition, especially the competition between the enterprises in the same industry is becoming increasingly fierce. Under such pressure, the enterprises must have to build up their own strength by scientific methods for a better survival and development. In this way, corporate internal management becomes particular important. Corporate internal information management is an important part of cooperate internal management, and information acquisition is important for both the management and the ordinary employees in an enterprise. Therefore, the timely and quick acquisition of information is the key to improving the competition of the enterprises. There are many sorts of cooperate internal information and the information system mainly include the information with high use rate to settle the issues of internal news and technologies. Thus, it cannot only intensify corporate internal management, and also improve internal operating efficiency and strengthen corporate competitiveness [5].

Corporate internal management information system covers part functions of corporate internal information management. It realizes system management by adding, deleting and changing the users, and by the functions of information addition, deletion, revision and query. Cooperate internal users can conveniently acquire the needed information through fuzzy query. The unique dual access mode of the system makes the management and retrieval implemented in hierarchical manners, and also makes the system safer and easier for maintenance. The system supports wide area network retrieval, which can greatly reduce the convenience brought by time and location [2]. 
The corporate internal management information system developed by $\mathrm{B} / \mathrm{S}$ structure can better settle the matters of space and time in the corporate internal information, and greatly improve corporate internal operating efficiency. Now, the corporate internal management information system based on Web has enjoyed a robust development and a wider application in government, schools, hospitals and enterprises. At present the internet has taken a deep root in the society and the application of computer has also become a widespread trend, specially the realization of computerized operation in the medium and large-sized enterprises. Corporate internal management information system is right developing based on the computer and internet.

\section{System Demand Analysis}

Task overview. The system construction shall include the following parts:

Build official document addition system, and the information addition personnel can classify and store the information by their types; the added information shall include the title, subtitle, author, key words, contents, and extracts of the official documents.

Build backend maintenance system, including the management over the users and senior users, and realize the hierarchical authorization management of the platform; the personnel in the same department shall enjoy the same authorization and form a system user group for internal management.

Build safety management. The information can be verified by distributed type-in and synchronous verification to make sure the standardization of the information and addition efficiency. The information base has functions of automatic back-up and firewall and provides safe and steady information service.

Build search administration procedure, build full-text index database for the fields of the title, extract and contents of the official documents, and all the contents can be possible for title retrieval and full-text retrieval.

The final user of the system is the enterprises in different financing and management modes. The operators and the maintenance personnel also have different educational and technical levels. Therefore, the investors shall see the future growth value of the enterprise, the salesmen shall see its current operation value, and the managers shall make comprehensive judgment of the two points. What's more, not all the information holds analytical value for the personnel in different functions and powers. The system platform have already loaded in the data base all the information, materials and data perhaps needed by the customers as the enterprises make the order. The personnel related in the enterprise can load any time their own materials and the information they collect.

Function specification. User management modules

Log-in function and the administrator's management modules. Refer to table 1 
Table 1 user management modules

\begin{tabular}{|c|c|c|}
\hline Input part I & The part for disposal P & Output part O \\
\hline $\begin{array}{c}\text { 1. type in user's information on } \\
\text { log-in interface }\end{array}$ & 1. judge if it is the administrator & $\begin{array}{c}\text { 1.if yes, skip to the } \\
\text { administrator interface; if no, } \\
\text { skip to common user interface }\end{array}$ \\
\hline $\begin{array}{c}\text { 2. after the administrator logs in, } \\
\text { type in the user's information to } \\
\text { be added on the user addition } \\
\text { page }\end{array}$ & 2. judge if the name repeats & $\begin{array}{c}\text { 2.if yes, type in the wrong } \\
\text { information; if no, skip to the } \\
\text { administrator start page }\end{array}$ \\
\hline $\begin{array}{c}\text { 3. type in hyperlink request on the } \\
\text { administrator page }\end{array}$ & $\begin{array}{c}\text { 3. query all the users and display } \\
\text { by paging }\end{array}$ & $\begin{array}{c}\text { 3. display all the information of } \\
\text { the user on each page }\end{array}$ \\
\hline 4. Type in user's ID & 4. operate user's information & $\begin{array}{c}\text { 4. display the changed user } \\
\text { information }\end{array}$ \\
\hline
\end{tabular}

Official document module:

Add official documents by typing official document information. Refer to table 2

Table 2 official document management module

\begin{tabular}{|c|c|c|}
\hline Input part I & Part for disposal P & Output part O \\
\hline $\begin{array}{c}\text { 1. add official document } \\
\text { information }\end{array}$ & $\begin{array}{c}\text { The system automatically acquire } \\
\text { timestamp and add information, and query } \\
\text { all the documents display by paging }\end{array}$ & display official document list \\
\hline $\begin{array}{c}\text { 1. type in official } \\
\text { document ID }\end{array}$ & 2 operate official document information & $\begin{array}{c}\text { display the changed official } \\
\text { document list }\end{array}$ \\
\hline
\end{tabular}

Official documents retrieval module:

Type in title and the key words of the contents for retrieval. Refer to table 3

Table 3 official documents retrieval module

\begin{tabular}{|c|c|c|}
\hline Input part I & Part for disposal $\mathrm{P}$ & Output part $\mathrm{O}$ \\
\hline $\begin{array}{l}\text { 1. type in the key words of the } \\
\text { official document title }\end{array}$ & $\begin{array}{l}\text { 1. Query all the official documents } \\
\text { corresponding to the title, and display } \\
\text { them by paging and the key words } \\
\text { are displayed in red }\end{array}$ & 1. display official documents \\
\hline $\begin{array}{l}2 \text { type in the official } \\
\text { documents key words }\end{array}$ & $\begin{array}{l}\text { 2. Query all the official documents } \\
\text { corresponding to the content and } \\
\text { dispose them by paging }\end{array}$ & $\begin{array}{l}2 \text { display the official } \\
\text { documents }\end{array}$ \\
\hline
\end{tabular}

\section{System design}

Overview design. For information retrieval, the basic demand is to type in the associated information to query the needed official document or the abstract. This is the function of the frontend and also the primary objective of the system. The backend is at the management level, and only the backend management can realize information retrieval at the front end.

System overall structure. System overall diagram: 


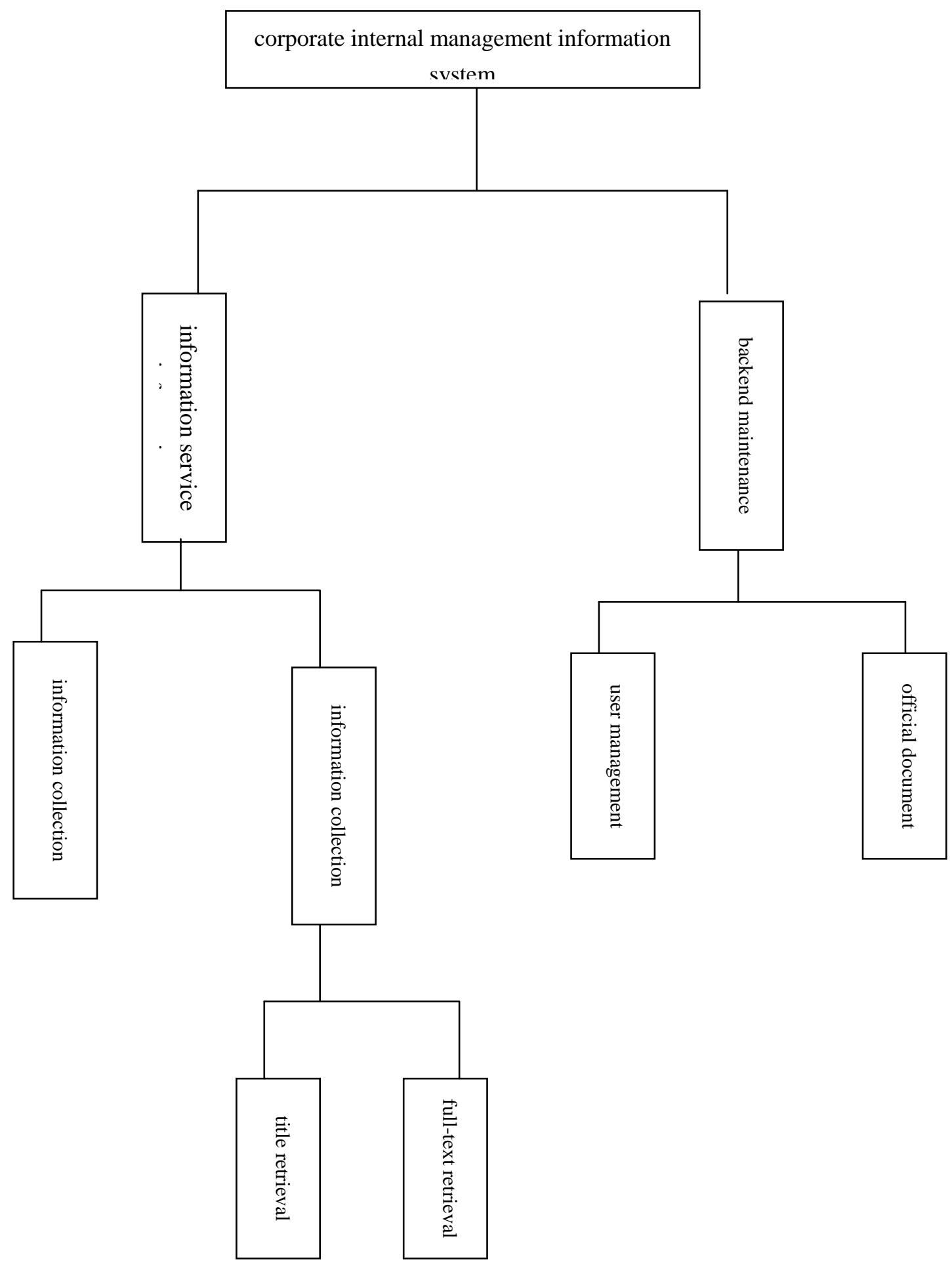

Fig. 1 system overall diagram

Major function modules. The function of the corporate rival electronic monitoring system will be briefly discussed in the section

Home page

Module description: direct to the home page index.jsp after user log in, and convenient to go back to the home page any time, url:/CIS/index.jsp

User management 
Description of the module: the operation of information addition, deletion and revision by the administrator

Input: url:/ CIS/ loginServlet

Disposal process: the system queries user information from the data base, displays the user information in list, and conducts the operations of user addition, deletion and level revision.

Output: user's name, password, department, sex, address, confidentiality level and operation

Official document management

Description of the module: the operation of information addition, deletion and revision by the administrator

Input: url:/ CIS/ loginServlet

Disposal process: the system queries official document information from the data base, displays the official document in the form of list, and conducts the operations of official document addition, deletion and level revision

Output: title, author, sketch, date of release, origin, level, confirmation for release, operation

Official document

Description of the module: the query for the official document and the detailed operation by administrator or the common user

Input: url:/ CIS/ loginServlet, type in key words

Disposal process: the system queries official document information, displays the official document in the form of list, and conducts official document query operation by key words.

Output: title, author, sketch, date of release, origin, level, confirmation for release, operation

System structure and solutions. System structure will adopt Browser/Server technology, overall support browser visit to reduce the work load for system maintenance and make the system more convenient for use. Meanwhile, the security of the information is also a very important problem, and it requires careful research and enough emphasis for the identity authentication of the user.

System platform selection:

The following selection program will be followed in regard to the selection of the major system platform. The program is not on based on the current demands and the understanding of the system platform products and application products under support, and also the one making full use of individual technical advantages.

Technical program is the overall solution program with J2EE technology as the main part. This technology is chosen, for one thing, it is because it is now used by all the application systems, and for another, it is because the deployment of the software is quite easy and will produce superior performance judging from the term of technology.

Operation procedure:

The system uses MVC) model-view-control) model to construct the overall structure. Layer $\mathrm{M}$ is responsible for the operation related to data base; layer V I responsible for business-related operation; and layer $\mathrm{V}$ is responsible for the operation related to display. The user can submit requests at layer $\mathrm{V}$, layer $\mathrm{C}$ receives the requests from layer $\mathrm{V}$ and disposals the requests by use of the modules at layer $\mathrm{M}$, and then returns the disposal results to the user.

\section{Data Base Design}

Detailed design. Instruction for user management module design 
Procedure description

Objective: get the administrator the ports for managing all the users, and make it convenient for the administrator to get the user under control

Features: non-resident memory, no requirement for coverage, sequential disposal

Function:

1. Add users

2. Display the user list by paging

3. Revise individual user information

4. Delete individual user

5. Delete multiple users from the group

In item:

User log-in

Type in user name and password, and judge it is the administrator or the common user according to the field in the data base list.

User addition

Type in the basic information of the user

Name, password, department, sex, address, telephone, e-mail, level ID, role Id

3. Display all the users by paging

The current page (pagenum), the number of displays on each page (num)

Revise individual user information

1) type in user ID, and check his detailed information according to the ID

2) password, department ID, sex, address, telephone, email, level ID, role ID

Output:

1. User log-in

The administrator can get into the backend management page and the common user can get in common retrieval page (search_commmon.jsp) after successful login.

User addition

Return to backend management page after successful addition, or return to user interface in case the addition fails.

display user list by paging:

Output all the basic information of the user

name, password, role and level

Revise individual user information

Output user name. In case the revision succeeds, return to management user interface (use list page), and prompt successful revision; in case the revision fails, return to management (use list page), and prompt the failure of the revision

Instruction for official document management module design

Procedure description

Objective: get the administrator the ports for managing all the official documents, and make it convenient for the administrator to get the official documents under control

Features: non-resident memory, no requirement for coverage, sequential disposal

Function :

1. Add official documents

2. Display all the official documents by paging 
3. Display the official list corresponding to the column by paging

4. Revise individual official document

5. Delete and release official documents

6. Release group official documents

Output:

Add official documents

Official document ID item, sub item, title, author, origin, level, digest, content. Among official document ID consists the ID of item, sub item and the current time (System.currentTimeMillis ()$)$

Display official documents by paging

Current page (pagenum), the number of displays on each page (num) and item ID

revise official document information

Official document ID

delete and release official document (individual)

Official document ID selected

delete and release the official documents (batch)

Multiple official document ID selected

Output:

add official document

Return to backend management page if the revision succeeds; or return to the official document page in case the addition fails.

Display official document list by paging

Display the corresponding titles, authors, sketches, dates of upload, dates of issue, origins, levels, and confirmation for release

Revise official document information:

In case the revision succeeds, return to official document list and prompt successful revision; in case the revision fails, return to official document list, and prompt the failure of the revision。

Delete and release official document (individual)

In case the operation succeeds, return to official document list and prompt the success of the operation; or else, the failure of the operation will be prompted.

Delete and release official documents (batch)

In case the revision succeeds, return to official document list and prompt the success of the batch operation; or else, the failure of the operation will be prompted.

Instruction for retrieval module design

Procedure description

Objective: make it convenient for the user to query the need information

Features: non-resident memory, no requirement for coverage, sequential disposal

Functions:

1. Common retrieval

2. Advanced retrieval

3. Display the results by paging

Output:

1. Common retrieval: 
Key words, select requery or query in results

Advanced retrieval

Key words, select title query or full-text query, select data base (item), select the number of display on each page, select all the retrieval, or retrieve by date (the dates of beginning and end)

The results displayed by paging

The current page (pagenum), the number of displays on each page (num)

Output:

1. Common retrieval

The results will be displayed by paging in case the query succeeds; no result to display in case the query fails.

advanced retrieval:

The results will be displayed by paging in case the query succeeds; no result to display in case the query fails.

The problems to be solved yet

The advanced retrieval function remains to be realized yet. The advanced retrieval means the second retrieval based on the primary.

\section{System Realization and Test}

System introduction. The system is corporate internal management information system, mainly used to help enterprise internal staff browse and read internal articles of incorporation and system. The frontend mainly functions for fuzzy query to help the user acquire the needed information; while the backend has a complex function, mainly helping the administrator with system management, since the administrator can act in the highest authority and get the user and official documents under control by adding, deleting and revising the information.

System interface. System login interface:

The information input through login interface can help judge the authority of the users. The common user and the administrator shall their special file retrieval interfaces.

Official document retrieval interface:

Get into official document retrieval interface by common user verification. The common user can add key words and enjoy the retrieval function on this interface. The related information can be read by retrieval or be read directly without retrieval

Official document reading interface:

Acquire detailed information by reading official document directly or through retrieval, and browsing the full-text of the official document can help the user directly acquire related information.

Management interface:

Get into user management interface by verifying the ID of the administrator on login interface. The administrator can add, delete and revise the user information on the management page. The interface has a strong orderliness, visual page and convenient operation

Use registration interface:

The administrator clicks the button of user registration to get into user registration interface, where the administrator can add the user's name, password, department ID, address and telephone. 
Official document management interface:

The administrator clicks the button of official management to get into official document management interface where the user can add, delete, revise the official documents. When the new official document are added, there will display the time of addition to indicate their ages, so the common users can judge if they need to browse the official document in the process of retrieval. The administrator can also make batch deletion of the official document once for all, in case of plentiful of the old official documents to make it convenient for management.

Official document addition interface:

The administrator clicks the button of adding new official document to get into official document addition interface, where the administrator can release official documents, or add their titles, authors, introduction and contents before release.

\section{Acknowledgements}

This work was financially supported by project of Technology Department of Jiangxi Province [No 20143BBM26048] and project of Jiangxi University of Technology [No. xtcx201312].

\section{Reference}

[1] Zhang Haipan. Software Engineering. Posts and Telecom Press.2003.114 116.

[2] Chang Jinyi, Zhou Bei. Management Information System. China Electric Power Press.2005.150 153 .

[3] Y.Daniel liang. Introduction to Java Programming. China Machine Press.2002.34 35.

[4] Fields Kolb. Web Development with JavaServer Pages. Manning Press.2006.100 110.

[5] Wang kaoyi, Liu Zhongbing, Xue Jiajing. JSP Data Base Development Strength Essence. Electronic University Press.2005.78 150 .

[6] Zhao Wenwu. Complete Application in Real Practice of the New Weapon for Webpage Making --Dreamweaver MX 2004（Chinese version）. China Aerospace Press.2005.10 11.

[7] (America) Berthold Dawm, Li Hua, Li Zhengyi (translation).Eclipse 3 Advanced Programming. Tsinghua University Press.2006.55 56.

[8] Zhang Dazhi, Ying Qun. Proficiency in Eclipse. Tsinghua University Press.2006.20 25.

[9]He Min.JSP Advanced Development and Application. Science Press.2003.183 190 . 